\title{
No(n) nada, no(n)nada. De los textos legales de la Edad Media a la literatura del Siglo de Oro
}

\author{
Carmela Pérez-Salazar* \\ Griso - Universidad de Navarra, España
}

\begin{abstract}
Resumen
En estas páginas se revisa el recorrido histórico de nonada, cuantificador de existencialidad negativa y sustantivo que alcanzó difusión en el Siglo de Oro. Además de rastrear los entornos sintácticosemánticos que hicieron posible la combinación del adverbio no(n) y los indefinidos ninguno y nada, se analizan diacrónicamente la progresión cuantitativa, el comportamiento gramatical, los valores y la distribución social y textual del nuevo elemento nonada. Según se puede apreciar en el CORDE, no(n) nada o no(n)nada (las dos representaciones se emplean indistintamente) se documenta con todos sus valores en el siglo XV. Nada y nonada se especializan, como sustantivos, en significados diversos, pero mantienen siempre un margen coincidente en empleo libre y como integrantes de unidades fraseológicas. Esa concurrencia es, posiblemente, la que provoca que nonada, sin un espacio exclusivo, inicie en la segunda mitad del siglo XVII un retroceso irreversible, que, en cualquier caso, apenas encuentra eco en los repertorios lexicográficos. Resulta testimonial, respecto de la limitación temporal de la vigencia de este elemento, su escasa presencia en el español americano.
\end{abstract}

* Para correspondencia, dirigirse a: Carmela Pérez-Salazar (cpsalazar@unav.es), Departamento de Filología, Edificio Biblioteca, Universidad de Navarra, Campus Universitario 31009 Pamplona (Navarra), España. 
Palabras clave: castellano medieval, español clásico, indefinidos de existencialidad, negación, nonada.

\title{
$N O(N)$ NADA, NON(N)ADA. From Medieval LEGAL teXts to GoldEN Age Literature
}

\begin{abstract}
This article reviews the historical trajectory of nonada, a noun and quantifier of negative existentiality well spread in the Golden Age language. Firstly I track the syntactic-semantic contexts that allowed the combination of the adverb no(n) and the indefinites ninguno and $n a d a$, and then I present a diachronic analysis of the quantitative progression, grammatical behavior, meanings and social and textual distribution of the new element nonada. The CORDE shows that no(n) nada and no(n)nada (both representations were used without distinction) is documented with all its values in the 15th century. As nouns, nada and nonada specialize in different meanings, but they always keep a common space of use as free sequences and elements pertaining to idioms. This concurrence may be the reason why nonada (which never had an exclusive space) initiated an irreversible retreat in the second half of the 17 th century, even though this process was scarcely documented in lexicographic repertoires. With regard to the limited temporal vigency of this element, it should be also noted that nonada had little presence in American Spanish.
\end{abstract}

Key words: Medieval Castilian, Classic Spanish, indefinites of existentiality, negation, nonada.

Recibido: 07/03/14 Aceptado: 20/05/14

\section{INTRODUCCIÓN ${ }^{1}$}

Si hay un grupo de elementos que experimenta variaciones a lo largo de la historia del castellano-español, es el de los cuantificadores de

1 Este trabajo se inserta en el Proyecto de Investigación Autos Sacramentales completos de Calderón. Edición crítica (Fase final). Ministerio de Ciencia e Innovación. Gobierno de España. FFI2011-26695. 
existencialidad. La sucesión de cambios acontecidos a lo largo de la Edad Media en el inventario de formas culmina, al terminar el Siglo de Oro, con la configuración del paradigma moderno de existenciales positivos y negativos organizado en seis elementos (alguien, alguno, algo; nadie, ninguno, nada) ${ }^{2}$. Pero, incluso desde entonces, es posible encontrar otras formas y fórmulas de distinta naturaleza condicionadas diatópica, diastrática y diafásicamente.

La bibliografía dedicada a los cuantificadores existenciales positivos y negativos es abundante. A los trabajos clásicos que versan sobre indefinidos de existencialidad en la historia del español (Malkiel 1945 y 1948; Montgomery 1965; Corominas 1987-1991: s.v. nacer) han venido a sumarse, recientemente, estudios igualmente imprescindibles sobre la evolución de los recursos que el español emplea para manifestar indeterminación, impersonalidad o indiferencia referencial (Company 2009) ${ }^{3}$. Indispensables son también las páginas dedicadas a la gramática de la negación en las lenguas romances, en la que se ven involucrados los indefinidos de existencialidad negativa ${ }^{4}$, y en concreto las que versan sobre el cambio sintáctico que culmina, en español, en el siglo XVI, y que supone la desaparición de la doble negación preverbal ${ }^{5}$.

Pese a tan dilatada atención, se echa de menos un estudio diacrónico dedicado exclusivamente a nonada, cuantificador y sustantivo del que los

2 Eberenz (2000: 413-436); Ricós (2002: 956-957) y Girón (2004: 865) se refieren a estos cambios.

3 En este capítulo sobre los indefinidos compuestos y los pronombres omne y uno, la autora presenta el estado de la cuestión (Company 2009: § 10.3). También Raya García (1992) y Espinosa y Sánchez Lancis (2006) se ocupan de los indefinidos en castellano medieval; Rueda (1997) revisa el comportamiento gramatical de los elementos negativos en español - entre estos, los indefinidos- desde la Edad Media. Pérez-Salazar (2007) examina el paradigma de los cuantificadores y otros indicadores de indeterminación en textos no literarios de los siglos XVII y XVIII; y Ricós (2002 y 2003) aborda la evolución de los recursos expresivos de existencialidad o indeterminación. Eberenz (2000: 413-435) se detiene, entre otros elementos, en la nómina de indefinidos de existencialidad en el castellano siglo XV.

4 Relacionar todo lo escrito al respecto excedería el propósito de estas páginas; en un trabajo reciente, García Cornejo (2009: 354) señala precisamente que la bibliografía sobre la negación, sobre todo la dedicada a las lenguas romances, es casi inabarcable. Remito a este artículo para una información bibliográfica actualizada, y para una propuesta sobre las causas y la cronología del cambio que experimentan los esquemas negativos en torno a nunca, ninguno, nada y nadie, y que esta autora concibe como un ciclo, como un proceso gobernado por los principios de mutabilidad y estabilidad que ya presentaban Martinet o Coseriu.

5 A ello se refieren Llorens (1929: § 18); Keniston (1937: § 40.4); Rueda (1997: 169170); Sánchez López (1999: 2568-2569); Camus (1986 y 2006: 1195-1200); García Cornejo (2009: 355 ss.). Posner (1985), Camus (1987-88) y Martins (1997) se ocupan de la evolución sintáctico-semántica de cuantificadores negativos del latín a diversas lenguas romances. 
diccionarios informan desde el Siglo de Oro hasta la actualidad, pero que, atendiendo a su presencia textual, inicia su andadura en la Edad Media y parece tener fecha de caducidad en los albores del español moderno. Convencida de la oportunidad de describir monográficamente este elemento multicategorial-recientemente he tenido ocasión de investigar sobre algunas cuestiones relativas a los indefinidos de existencialidad negativa ${ }^{6}-$, me propongo mostrar en estas páginas, tomando como fuente de análisis las bases de datos académicas (esencialmente el Corpus Diacrónico del español ${ }^{7}$ ), el origen, la extensión, el comportamiento gramatical y los significados de nonada, que, según se ha dicho, era característicamente oral ya en el siglo XV (Eberenz 2000: 423) ${ }^{8}$.

\section{CUANTIFICADORES Y ADVERBIO DE NEGACIÓN. NON NINGUNO, NON NADA Y NONADA EN LA EDAD MEDIA}

2.1. No es, pues, mi propósito ocuparme de la paulatina desaparición de la denominada doble negación preverbal ${ }^{9}$, cuestión esta generosamente tratada, interpretada y revisada, como acabo de indicar. Tan solo recordaré

6 En concreto sobre los valores y funciones de las formas nada, cosa y nonada en el Siglo de Oro y sobre algunas unidades fraseológicas construidas en torno a estos elementos (Pérez-Salazar 2012 y 2013).

7 Reproduciré los testimonios del CORDE sin modificaciones, salvo en la puntuación, que modernizo en algún caso para facilitar la comprensión. Señalaré, en este orden, fecha, autor y obra.

8 Eberenz (2000: 423-424) se refiere a nonada como variante formal de nada. Son muchos los datos que aporta este autor sobre nonada, que encuentra en el siglo XV sobre todo "en los pasajes que reflejan la lengua hablada". De su arraigo en este tiempo, indica, sirven de testimonio los empleos idiomáticos.

9 Denominación impropia para el romance, según García Conejo (2009: 360-369), que considera (y justifica) que las formas nunca, nadie, ninguno y nada son positivas hasta el siglo XV, de ahí su compatibilidad con el adverbio no(n). Adquirido el significado negativo, que sucede antes con nunca y ninguno, la doble presencia resulta redundante. Sobre el comportamiento de las palabras negativas (mots-N) respecto de otra negación en distintas lenguas romances (concordancia negativa), véase Corblin y Tovena (2003: 301-309). En pp. 310-323 ofrecen una revisión del tratamiento que ha recibido esta cuestión. Para una descripción del comportamiento gramatical de los denominados términos de polaridad negativa (TPN) en español actual, entre los que se encuentran nada, nadie y nunca, véase Bosque (1980: 21-26). El mismo autor (pp. 49-50) explica la diferencia -tomada de Tesnière- entre palabras negativas permeables y no permeables. En español y en francés las mismas palabras cumplen ambas funciones, puesto que se construyen con o sin otra negación. 
el alcance de la compatibilidad, en textos medievales, de los indefinidos de existencialidad negativa y el adverbio $n o(n)$. La copresencia de los existenciales negativos con el adverbio se produce cualquiera que sea la posición de aquellos respecto del verbo; así, junto a los casos de distribución a ambos lados del núcleo verbal oracional - posibilidad que continúa hasta nuestros días- es habitual hasta el siglo XV la concurrencia preverbal de adverbio e indefinidos, como en los casos que siguen ${ }^{10}$ :

1. E destos morauedis somos pagados, e nada non finco por pagar (1240. Anónimo, Documentos [Documentos del Monasterio de Santa María de Trianos])

2. E asy yendo por el camjno demandaua el Conde a Remondin de su esposa mas el nada no le dizia de que el conde era bien triste (1489. Anónimo, Historia de la linda Melosina)

3. Et mando e deffiendo firme mientre que ninguno non sea osado de uenir contra esta mi confirmacion (1250. Anónimo, Documentos [Documentos del Monasterio de Santa María de Trianos])

4. E otrosi todos los que este sacramento reçibieren \& presentarlos al obispo \& deuen amonestar a todos los que fueren de edad que quisieren reçebir este sacramento [...] \& ninguno no lo deue reçebir mas de vna vez (1491. Anónimo, Siete Partidas de Alfonso X)

5. Mandamos que nadie non reciba sobreleuador, si nón qui ouiere casa con pennos en la cibdat (1300. Anónimo, Fuero de Plasencia)

6. La qual queriendo nos mandar publicar en las yglesias cathedrales, a fin que nadi no pudiesse allegar ygnorancia de aquella, se ha seguido entre algunos obispos y prelados (1495. Anónimo, Fernando al cardenal de Sigüenza rogándole consiga del papa un breve...)

2.2. Pero la compatibilidad de los existenciales negativos con el adverbio no se agota en los casos expuestos. Los indefinidos ningun(o) -y variantes formales o flexivas ${ }^{11}$ - y nada $^{12}$ se encuentran, en el mismo tiempo,

10 Estos y otros testimonios medievales en Ricós (2003: 261-262); Camus (2006: 11751178); y García Cornejo (2009: 360 ss.).

${ }_{11}$ Ningun(o) se emplea como pronombre o como determinante, con referente personal o no personal, y esto es válido para todas las épocas.

12 Como anota y documenta Llorens (1929: 105-106), nada se construye también sin otra negación desde las primeras manifestaciones romances. 
inmediatamente precedidos de $n o(n)^{13}$. La copresencia de no(n) y ningun(o) es la más visible entre los siglos XIII y XIV, y, sin embargo, no va a dar lugar a un nuevo elemento, como sucede con no(n) y nada, de cuya concurrencia contextual surge el cuantificador-sustantivo que aquí se analiza, nonada.

En la tabla que sigue se puede observar la progresión cuantitativa por centurias (siempre según el CORDE) de las combinaciones no(n) ningun(o) o no(n) nengun(o) -y variantes flexivas-, no(n) nada, y de la forma lexicalizada no(n)ada durante la Edad Media, cuyos valores se analizan a continuación:

Tabla 1. No(n) ninguno o no(n) nenguno, no(n) nada y no(n)ada en la Edad Media

\begin{tabular}{|c|c|c|c|}
\hline & $\begin{array}{c}\text { no(n) ninguno, } \\
\text { no(n) nenguno }\end{array}$ & no(n) nada & non(n)ada \\
\hline Siglo XIII & 25 & 1 & 0 \\
\hline Siglo XIV & 29 & 12 & 3 \\
\hline Siglo XV & 92 & 63 & 21 \\
\hline
\end{tabular}

Los primeros testimonios de no(n) seguido de ninguno o nada visibles en el CORDE pertenecen al siglo XIII; aparecen en enunciados con verbo elíptico ${ }^{14}$, en concreto en estructuras coordinadas, en las que el segundo miembro, precedido del adverbio $n o(n)$, se introduce para precisar o para contrastar lo que se acaba de exponer:

7. Los testimonios que an a testimoniar alguna cosa antes que ren digan de la cosa deuen jurar que diran uerdat e no ninguna falsedat (1250-1300. Anónimo, Fuero General de Navarra)

13 Testimonios de non ninguno y non nada en Llorens (1929: 106-107). Wagenaar (1930: 26-30) se refiere a la forma pleonástica non ninguno en la Edad Media, y la considera herencia del latín vulgar. No encuentro, en cambio, testimonios de non nadi en la Edad Media, pero sí de no nadie en español clásico, como señalaré más adelante. Rueda (1997: 198-199) y García Cornejo (2009: 380-382) describen también estas combinaciones y aportan buen número de testimonios.

14 Sobre elipsis verbal y negación en períodos coordinados y yuxtapuestos y en diálogos, véase Bosque (1984). Camus (2006: 1179-1180) recoge testimonios medievales de los indefinidos nada y ninguno precedidos de non en oraciones con verbo elíptico, en respuestas a interrogativas parciales y en oraciones afirmativas. El autor interpreta también estos casos como resultado de la dependencia que los indefinidos nada y ninguno, que todavía no están marcados como elementos de contenido negativo, muestran, en la Edad Media, respecto del adverbio de negación.. Ya Bello (Bello y Cuervo 1847: 351) se refería a los elementos originalmente positivos -nadie, nada, jamás-que "hemos revestido de significación negativa". 
8. El senor de casa uaya en la hueste \& non ninguno otro por él (1300. Anónimo, Fuero de Baeza)

9. El ballestero de cauallo sabio en el arte que leuare ballesta con dos cuerdas e dozientas saetas, tome por ella racion entrega e por el otra no nada (1296. Anónimo, Fuero de Alcaraz)

Obsérvese que los textos en que se introducen estos períodos coordinados son documentos notariales y ordenamientos legales, redactados, por cierto, en distintas modalidades romances, en los que es sabido que el afán de exactitud gobierna con frecuencia la redacción y conforma un estilo característico. Pero la concurrencia inmediata del adverbio negativo y el cuantificador ninguno sucede además en un proverbio:

10. Por esso dize el prouerbio en Castilla: Alcarauan fadiduro, que a todos da consejo e a si non ninguno (1293. Anónimo, Castigos e documentos para bien vivir ordenados por el rey Sancho IV)

Así pues, pese a la escasez testimonial, este siglo aporta datos de indudable interés. La anteposición inmediata de no(n) a los cuantificadores ninguno y nada se produce por circunstancias que sobrepasan los límites del sintagma en el que se encuentra el cuantificador; el rigor expositivo característico de los textos legales o la estructura bimembre que adoptan los refranes ${ }^{15}$ generan contextos sintácticos que facilitan la elipsis del verbo, y esta provoca el encuentro de adverbio e indefinidos. Queda, asimismo, atestiguado que la presencia de $n o(n)$ ninguno y no(n) nada se produce en lo escrito y en lo oral, en la distancia de los textos legales y en la coloquialidad de los proverbios ${ }^{16}$.

En el siglo XIV continúa, en buena parte, lo expuesto hasta aquí, y al mismo tiempo se amplía la frecuencia de estas combinaciones (especialmente la de no y nada), y, sobre todo, la casuística. La coocurrencia de adverbio e indefinidos negativos se localiza especialmente en textos legales, pero alcanza otros géneros, en prosa o en verso. La elipsis del verbo explica

15 Aunque no es un rasgo esencial, la organización bimembre se tiene como prototípica en los refranes, como indica Anscombre (1997: 45-53).

16 No incluyo entre estos casos como el que sigue, excepcional en este tiempo, en el que no y nada se suceden inmediatamente en un diálogo, ya que, separados por coma por el editor, constituyen enunciados independientes, y conforman una doble respuesta negativa a una interrogativa total: E dixo les: Quando uos enuie sin saclito, e sin talega, e sin calçado, ¿fallecio uos alguna cosa? Ellos dixieron: No, nada (1260. Anónimo, El Nuevo Testamento según el manuscrito escurialense I-j-6. Desde el Evangelio de San Marcos...). Camus (2006: 1179) ofrece testimonios más tardíos en interrogativas parciales, en las que non y nada sí constituyen una única respuesta, como los que analizaré más adelante. 
de nuevo la sucesión inmediata de adverbio e indefinido en el segundo tramo de una coordinación, como las arriba descritas, o bien, en pasajes dialogados, en el enunciado que constituye la respuesta a una pregunta. A este siglo pertenece, además, el primer testimonio de no nada en un contexto que favorece la incorporación de una negación expletiva (la estructura comparativa de 15$)^{17}$.

11. [...] porque alas malas costumbres se sieguen muchos males, \& no ningunos bienes (1300-1330. Anónimo, Fuero General de Navarra)

12. ¿Qui es aquell que caualca con si mismo en afferes d'otri?

Quasi que diga: Non ninguno (1376-1396. Juan Fernández de Heredia, Libro de actoridades)

13. La ora ueries toda la tierra en antiguo silençio, non ninguna uoz, no ningun siluo de pastor (1385. Juan Fernández de Heredia, Gran crónica de España, I)

14. Dan á los de lara e vizcaya cada año seis mrs. por el sant johan alos otros non nada (1352. Anónimo, Becerro de las behetrías de Castilla)

15. [...] e bien saben todos que vos non traedes/ ropa ninguna que sea sencilla./ Por ende, sería a mí grant manzilla/ si de vos oviesse ropa desdoblada,/ pero más vale algo que no nada (1379-1425. Alfonso de Villasandino, Poesías [Cancionero de Baena])

Ahora bien, la coincidencia de adverbio y cuantificador negativo sucede también fuera de estas circunstancias, aunque con posterioridad y excepcionalmente: en el testimonio que sigue puede decirse que el indefinido, ubicado en el marco de un sintagma preposicional (en el que, obsérvese, aparece otro cuantificador), recibe el refuerzo negativo del adverbio ${ }^{18}$. Esta centuria trae, además, las primeras documentaciones de la forma lexicalizada nonada (cfr. infra):

16. En los tiempos del qual, ya sea que muchas batallas estranyas et ciuiles se leuantasen, empero fueron pacificadas por no nenguna o por poca sangre (1377-1399. Juan Fernández de Heredia, Traducción de Breviarium ab urbe condita, de Eutropio)

17 Sobre contextos que favorecen la negación expletiva, véanse Martíns (1997: 197-200); Camus (2006: 1183-1184); Sánchez López (1999: 2627-2630); Corblin y Tovena (2003: 294299). Bosque (1980: 68-69) llama superflua o espúrea a este tipo de negación de las oraciones comparativas, e incluye las explicaciones que han aportado algunos gramáticos al respecto.

${ }_{18}$ Así pues, en este caso la negación afecta solo al indefinido. Véase Sánchez López (1999: 2565-2567) sobre negación de oración, negación de sintagma y negación de palabra. 
Valga destacar que este pasaje (y los testimonios de no nada y nonada reproducidos más abajo) se encuentra en una traducción firmada por el aragonés Juan Fernández de Heredia -cuyas peculiaridades lingüísticas ya han merecido atención ${ }^{19}$ - al que se debe, además, la mayor parte de los testimonios de no(n) ningun(o) y no(n) nada de este tiempo. Precisamente este autor, en sus producciones en aragonés, emplea generosamente la combinación non res o non ren. No cabe descartar que Heredia traslade estas secuencias de una a otra modalidad romance; sea como fuere, su excepcionalidad consiste en anticipar lo que en otros textos y autores se puede observar muy poco tiempo después.

Me permito anotar, respecto de no(n) res o no(n) ren, que en el CORDE solo se encuentra en textos aragoneses ${ }^{20}$. El número de testimonios supera con creces el de no(n) nada en castellano; casi todos, por cierto, pertenecen al autor mencionado ${ }^{21}$ :

17. E sy por auentura non fallaras arzilla o otra firme, suelta la vegada basta que los fundamentos entren de yuso de tierra la quarta parte de la altura de la casa. E non res menos deuedes fazer vuestro poder que la casa o tierra sea ornada \& ennoblesçida de vergeles \& de prados \& de muchos buenos frutales (1380-1385. Sayol Ferrer, Libro de Palladio) 18. [...] \& el principio de lur enamigança fue por no res (1379-1384. Juan Fernández de Heredia, Traduccción de Vidas paralelas de Plutarco, III) 19. Et esta cosa del començamjento pareçio cosa de no res; (13791384. Juan Fernández de Heredia, Traduccción de Vidas paralelas de Plutarco, III)

20. [...] la hora comjença de perder su splendor \& finalment torna a non ren, assin semblantment \& la mi uentura no esta jamas en vn punto

19 Respecto de las peculiaridades de Fernández de Heredia, Enguita (2004: 573) se refiere a la heterogeneidad lingüística de su producción, debida a "la participación en ella de traductores, escritores y correctores de distinta procedencia".

20 Res y ren son cuantificadores habituales en aragonés y navarro medievales, y se emplean tanto con valor positivo como negativo. Véanse Alvar (1953: 299), que aporta, precisamente, un testimonio de non res, y Saralegui (1977: 192), que documenta res en navarro (pero no non res) en los siglos XIII y XIV. Testimonios de res y ren y nulla res en textos castellanos y leoneses de los siglos XIII y XIV en Alcón (1920: 544-546).

21 En el siglo XIV, en el CORDE se pueden encontrar 212 testimonios de no(n) res (habitualmente en la secuencia non res menos) y non ren; de ellos, 194 están en obras y traducciones de Fernández de Heredia. Tampoco se ha de descartar que se trate, en este autor, de un uso tomado del catalán, modalidad en la que se producen secuencias similares (además de non res, son posibles no ningú, no cap y no gens) desde la Edad Media (Solà 1973: 117) hasta la actualidad. Morant (1993: 127) anota indicaciones sobre el valor expletivo de la negación y sobre la limitación al uso informal de estos refuerzos. 
(1379-1384. Juan Fernández de Heredia, Traduccción de Vidas paralelas de Plutarco, I)

Me refería arriba a las primeras manifestaciones de la unidad léxica nonada. Nonada -en 21 y 22 se observa que la alternancia con no(n) nada es posible en la misma obra- se ubica en dos secuencias precedidas de preposición que van a alcanzar notable difusión en español clásico, de nonada ('sin importancia'), y por nonada ('por un motivo insignificante') ${ }^{22}$.

21. [...] tanto era Niquia temeroso \& auia miedo de hombres de nonada (1379-1384. Juan Fernández de Heredia, Traduccción de Vidas paralelas de Plutarco, II)

22. [...] \& los donos qu'el daua eran prouisiones de ciudades, de castiellos, de tierras \& de gentes. \& aun casaua las gentiles muieres a lur mal grado con hombres de no nada (Ibidem)

23. Corazón, que por nonada/ ý curas tu perdición,/ siguiendo contra razón/ voluntat desordenada (1400-1440 Ribera, Suero de Poesías [Cancionero de Palacio])

La irrupción de nonada en lo que posiblemente eran ya entidades fraseológicas ${ }^{23}$ hace pensar que, como sustantivo ('cosa de escasa importancia'), gozaba ya de cierta difusión. No parece difícil acceder a este significado desde el que, como indefinido, no nada comparte con nada (esto es, 'ninguna cosa'). Nada, también sustantivo desde el siglo XIII ${ }^{24}$, se prefiere en cambio en este tiempo para el valor de 'ausencia de todo ser' (cfr. infra, testimonios 37 a 39, sobre nonada con este mismo significado):

24. Et una cosa que fizo de nada los Angeles, et los omes, et el cielo, et la tierra, et todas las otras cosas (1251-1255. Alfonso X, Fuero Real)

22 Obsérvense por no res y de no res en 18 y 19.

23 La fijación formal de ambas desde sus primeras manifestaciones textuales permite considerarlas así, si bien la idiomaticidad de estas secuencias es baja. Debo anotar la existencia de las variantes de nada y por nada, que alternan, respectivamente con de nonada y por nonada, y que, al desaparecer la unidad nonada, quedan como únicas en nuestro idioma. En cuanto a de nada, locución adjetiva, es cronológicamente posterior a de nonada, pero deja algún testimonio en el siglo XV, visible en el CORDE. Remito a Montoro del Arco (2006: 4042) para una reflexión sobre la fijación formal de las unidades fraseológicas, a García-Page (2008: 388-396) sobre la idiomaticidad como criterio fraseológico, y a Pérez-Salazar (2013: 259) sobre el grado de idiomaticidad de las locuciones en las que interviene nada.

24 Véase Llorens (1929: 35; 104-105 y 110-111) sobre la alternancia medieval de nada, res y cosa; y Eberenz (2000: 421-432) sobre nada, nonada, cosa, algo y fórmulas sintagmáticas en el siglo XV. 
25. [...] ca Dios nunca consiente, nin jamás consentirá,/ que el omne que Él crió de nada, padesçerá/ sin justiçia algunt mal, nin condenado será (1378-1406, P. López de Ayala, Rimado de Palacio)

2.3. Indicaba arriba que la denominada doble negación preverbal se extingue a lo largo del siglo XV y culmina su desaparición en español clásico (Llorens 1929: 32-33 $)^{25}$. Ajenas a este cambio, las combinaciones no(n) ninguno y no(n) nada y la unidad léxica non(n)ada aumentan en frecuencia y amplían sus posibilidades funcionales.

El incremento de la concurrencia de no y ninguno (o variantes) es llamativo ${ }^{26}$. Buena parte de los testimonios son idénticos a los ya descritos (casos de elipsis verbal o entornos que favorecen la negación expletiva -así en 26 a 29-). Sin embargo, como ya anticipaba Fernández de Heredia, la compatibilidad de non y los existenciales negativos (cfr. infra sobre nada) se ha trasladado a otros contextos. No(n) precede a ninguno (o variantes) cuando el indefinido forma parte de sintagmas preposicionales, y ahora también en sintagmas sin preposición. No existe un molde o género textual característico: unos y otros casos aparecen en la prosa -científica, literaria o cronística-y en el verso; en refranes ${ }^{27}$, en obras originales y en traducciones. A falta de un condicionamiento de este tipo, sí es constante la presencia en el entorno próximo de otros cuantificadores con los que ninguno se vincula sintáctica y semánticamente:

26. [...] mejor era que la fiziese aquel que era más sin pecado que no ninguno de nosotros (1430. Pedro de Corral, Crónica del rey don Rodrigo, postrimero rey de los godos [Crónica sarracina])

27. E vido por qué en unos lugares se engendravan grandes árboles e en otros pequeños, e en otros no ningunos (1430-1440. Alfonso de la Torre, Visión deleytable)

25 Es entonces, señala Camus (2006: 1124) cuando los indefinidos negativos adquieren "una nueva identidad negativa, que hace posible su presencia en posición preverbal ya sin el adverbio no". García Cornejo (2009: 366) explica que, a partir de entonces, el adverbio pasa a ocupar una posición subsidiaria en la representación de la negación.

${ }_{26}$ Obsérvese que ninguno y sus variantes flexivas se emplean también en este siglo con referentes personales y no personales.

${ }_{27}$ El que recoge Santillana (aquí testimonio 28) es el mismo documentado en el siglo XIII (testimonio 10). 
28. El alcarauan hadeduro, a todos da consejo y a ssi no ninguno (1454. Íñigo López de Mendoza (Marqués de Santillana), Refranes que dizen las viejas tras el fuego)

29. [...] assí que, ahunque en lo del mundo algo el Rey contra ellas tenga, en lo de Dios no ninguna cosa (1482-1492. Garci Rodríguez de Montalvo, Amadis de Gaula, libros I y II)

30. Si qujero verdat fablar/ muy pocas o no njngunas/ vy personas en ayunas (1430-1480. VV.AA., Cancionero de Salvá)

31. E tanto fué el seguir de la caça, que los doçientos hombres que heran de armas tornáronse en çiento, e de çiento en çinquenta, e de çinquenta en non ninguno (1454. Pedro Carrillo Huete, Crónica del halconero de Juan II)

32. [...] finca la muy bien casada,/ o como gentil morada/ donde no ninguno mora (1458. Gómez Manrique, Planto virtudes [Cancionero de Gómez Manrique])

33. [...] otrosi pocas vezes o no ninguna faze el almirante juyzio a çerca del gage de batalla (1477-1485. Fernando Mejía, Libro intitulado nobiliario vero)

34. Job ovo siete fijos, e de siete tornose a seis; e de seis tornose a çinco; e de çinco torno a quatro; e de quatro torno a tres; e de tres torno a dos; e de dos torno a uno; e de uno a no ninguno (1500. Fernando de Córdoba, Suma de la flor de cirugía)

También llamativa en esta centuria es la difusión de no(n) nada y su resultado léxico nonada. El número de testimonios visible en los textos está próximo a la centena, y aunque más adelante alcanza una presencia más generosa, en el siglo XV se manifiestan todas sus posibilidades funcionales.

Respecto de los contextos sintáctico-semánticos en que se encuentra, lo señalado para no(n) ninguno es válido para no(n) nada. La coaparición de no(n) y nada se explica en ocasiones por las circunstancias del entorno ya descritas (casos de negación expletiva o de elipsis):

35. E aqueste plazer será poca cosa, mas será más que no nada (14251450. Juan Rodríguez del Padrón, Bursario)

36. A oras tienen, a oras non nada (1431-1449. Gutierre Díaz de Games, El Victorial),

pero abundan los testimonios que se escapan a esta explicación. En cuanto a la difusión textual, no(n) nada o no(n)nada se encuentra raramente en textos de contenido legal, y, en cambio, se ha hecho frecuente, en cualquiera de sus valores, en crónicas, tratados y ensayos y en la creación literaria en verso y en prosa, en particular en la narrativa, y son muchos los autores que 
dejan testimonios de una u otra representación. Las dos variantes se utilizan, asismismo, en pasajes literarios dialogados y en refranes ${ }^{28}$.

Como sustantivo, no(n) nada o no(n) nada significa 'ausencia de todo ser' (al igual que nada en el siglo XIII -ver testimonios 24 y 25-), valor este para el que admite la presencia de un actualizador ${ }^{29}, \mathrm{y}$ también 'cosa sin importancia':

37. Señor, sé e creo que Tú me formaste/a la tu imagen de una nonnada (1435. Pero Vélez de Guevara, Poesías [Cancionero de Baena])

38. E tú, onbre mundano e de non nada fecho (1438. Alfonso Martínez de Tolado, Arcipreste de Talavera. El Corbacho)

39. [...] el qual Padre por su potencia lo vuo criado de non nada (1455. Pedro Marín, Sermones)

40. No tiene otra cosa riqueza, qu'es asy como calabaça, que en poco espaçio es fecho grande, e luego torna a nonada (1424-1520. Anónimo, Cancionero de Juan Fernández de Íxar)

41. [...] que el onbre mentiroso trae consigo la señal de su confusión en la fruente, que todo onbre dubda de lo creer \& lo tiene por no nada (1448. Anónimo, Traducción del Libro de las donas de Francesc Eiximenis)

Como indefinido, predomina la representación en dos componentes; desempeña funciones pronominales (como ya se indicó para ninguno, está vinculado a otro cuantificador -o a una cuantificación, como en 45- en el mismo contexto) y adverbiales:

42. Yo ya de razón sobrado,/ pero non nada menguado/ uide grand diuinidat (1407-1463. Anónimo, Sin título [Cancionero de Estúniga])

43. [...] mas en quenta muy errada/ quento poco, y es nonada,/ que en fin es pago de buenos (1424-1520. Anónimo, Cancionero de Juan Fernández de Íxar)

44. Por que non se deve ninguno maravillar porque el mal es tanto reprehendido, ca non nada de la naturaleza tiene, sobre lo cual es fundada toda la sancta Scriptura (1428. Enrique de Villena, Tratado de Astrología)

28 Eberenz (2000: 424) se refiere al uso de nonada en pasajes de El Corbacho que reflejan la lengua hablada, y anota además, respecto del arraigo que ya habría alcanzado, su presencia en secuencias idiomáticas.

${ }_{29}$ Nada y no(n) nada o non(n)ada encuentran, en estos casos, un contexto habitual junto a fazer, formar o criar. 
45. [...] cuyos secretos son ynotos a los muy sabidores, quanto más a los que nonada saben como yo (1445-1480. Gómez Manrique, Poesía con glosa [Cancionero de Gómez Manrique])

46. [...] esforçávalos que dexando el llanto, que poco o no nada aprovechava, a la demanda començada tornassen (1482-1492. Garci Rodríguez de Montalvo, Amadís de Gaula, libros I y II)

47. En tus vestiduras no nada compuesto te veo, y solías andar muy polido (1497. Juan del Encina, Égloga de Fileno, Zambardo y Cardonio) 48. Pármeno. [...] Todo para ti y no nada de que puedas dar parte. Pelechar quiere la vieja (1499- 1502. Fernando de Rojas, La Celestina. Tragicomedia de Calisto y Melibea)

Diálogos literarios y refranes de este tiempo permiten observar el uso de no nada como respuesta a interrogativas parciales, en las que, si bien se produce elipsis del verbo, parece evidente el realce expresivo de la negatividad:

49. 'Pues, dime, señora, ¿por qué lloras, que goze yo de ty?" Responde: "Non, por nada.”Pues, ¿qué cosa es ésta?” “¡Asý gozés de mí, n’os digo que non nada!" (1438. Alfonso Martínez de Toledo, Arcipreste de Talavera [Corbacho])

50. ¿Que lleuays ay? No nada, si el asno cae (1454. Marqués de Santillana (Íñigo López de Mendoza), Refranes que dizen las viejas tras el fuego)

Por último, destaca la difusión de las locuciones antes mencionadas; por nonada (o por no nada) y de no nada se encuentran en cualquier molde textual y representan, en este siglo, casi el $20 \%$ sobre el total de los testimonios de nonada y no nada que ofrece el CORDE:

51. Corazón, que por nonada/ ý curas tu perdición (1400-1440. Suero de Ribera, Poesías [Cancionero de Palacio])

52. ¡Quántas maravillas vistes y qué miraglos por non nada! (1438. Alfonso Martínez de Toledo, Arcipreste de Talavera (Corbacho))

53. Este desfallimiento es oy mucho en los onbres, \& todos tienpos rreyna por la mayor parte en las mugeres, que por no nada disfaman a sý mismas \& con grant plazer oyen mal de las otras (1448. Anónimo, Traducción del Libro de las donas de Francesc Eiximenis)

54. [...] os veo por casos de no nada sofrir que es marauilla (1470-1492. Juan de Flores, Triunfo de amor)

55. [...] aun por un pedaço de vidro y d' escudilla y por otras cosas de no nada les davan los indios cuanto querían (1492-1493. Anónimo, Diario del primer viaje de Colón) 


\section{NO NINGUNO, NO NADA-NONADA Y NO NADIE EN ESPAÑOL CLÁSICO. LA ATENCIÓN DE GRAMÁTICOS Y LEXICÓGRAFOS}

3.1. En el período áureo se inicia el retroceso textual de la combinación no ninguno, que ya no deja testimonios al concluir el siglo XVII. No nada o nonada -la forma lexicalizada predomina, por vez primera, en la segunda mitad del siglo XVI- alcanza en cambio una presencia aún más generosa que la expuesta hasta aquí; tal vez por esto sorprende el descenso repentino que experimenta al concluir este período, como se puede observar en la tabla 2 , que, en cualquier caso, coincide con la desaparición de otras formas y fórmulas del grupo de los cuantificadores de existencialidad que mencionaba al comenzar este trabajo ${ }^{30}$ :

Tabla 2. No ninguno, no nada y nonada en español clásico

\begin{tabular}{|c|c|c|c|}
\hline & no ninguno & no nada & Nonada(s) \\
\hline $1501-1550$ & 47 & 97 & 63 \\
\hline $1551-1600$ & 32 & 92 & 125 \\
\hline $1601-1650$ & 7 & 25 & 115 \\
\hline $1651-1700$ & 0 & 7 & 9 \\
\hline
\end{tabular}

Así pues, la regresión de nonada puede estar relacionada con el establecimiento definitivo del paradigma de los indefinidos de existencialidad, que se deshace de duplicidades para conformar un grupo más reducido en el que nada y nadie ya son términos negativos y se ha integrado el último miembro en incorporarse, alguien (Malkiel 1948: 369-371) ${ }^{31}$. La configuración de este paradigma no significa que los usuarios no recurran a otras formas de expresión, como, efectivamente, sucede ${ }^{32}$. El descenso en el número de

30 Girón (2004: 864-865) se refiere a la desaparición de hombre y cosa. En el segundo tramo del siglo XVII se observa también el retroceso de varias fórmulas sintagmáticas (PérezSalazar 2012: $\S$ 4.3).

31 Alvar y Pottier (1987: 143) señalan que en los siglos XVI y XVII tiene lugar "un largo camino hacia la eliminación o limitación de palabras multifuncionales (cosa, hombre)"; entonces se aceptan "formaciones más específicas como algo, nada, nadie”. Eberenz (2000: 418-420) observa que alguien se utiliza escasamente en el siglo XV, y anota su propagación en español clásico. Véase, además, Ridruejo (1989: 63-69) para una explicación de cómo sucede la evolución paradigmática.

32 Es, por ejemplo, el caso de uno, que, como describen Eberenz (2000: 443-446) y Ricós (2002: 950), fue adquiriendo difusión a lo largo del Siglo de Oro. 
testimonios alcanza también a nonada sustantivo, cuyo espacio semántico ('cosa de escasa importancia') no parece difícil de cubrir ${ }^{33}$.

Me permito indicar, por su excepcionalidad, que los escasos testimonios de concurrencia de no y nadie hallados en el CORDE pertenecen a este tiempo ${ }^{34}$; en todos ellos la elipsis del verbo permite explicar la aparición del adverbio. Pese a tan escasa manifestación, merece comentario, porque informa de la oralidad de estas coincidencias, el hecho de que cuatro de los cinco casos se encuentran en pasajes dialogados:

56. [...] fueron siete candeleros,/ dorados y muy luceros, / y en su medio a Cristo viste, / y no nadie circunstante (1508. Fray Ambrosio Montesino, Cancionero)

57. Antonica. [...] ¿Quién es?

Pandulfo. No nadie, pues que assí es/ que contino estáis reñiendo (1535. Anónimo, Auto de Clarindo)

58. - ¿Quién es vuestra merced?

El conde, que estaba muy arrepiso de haber venido al llamamiento del cardenal, respondió:

-No nadie, pues que venimos acá. (1574. Melchor de Santa Cruz de Dueñas, Floresta española)

59. Aguacil. ¿Cómo en su casa? ¿Quién es el amo desta casa?

Doctor. Yo soy, señor, que no nadie (1609. Anónimo, Entremés del doctor simple)

No ninguno se encuentra aún con cierta frecuencia en el siglo XVI. Además de los casos atribuibles a la elipsis (60 y 64), el español clásico ofrece más testimonios en los que el cuantificador está reforzado negativamente por el adverbio. Continúa la heterogeneidad de las fuentes, que no deja dudas respecto de su extensión:

60. El rey, cuando esto oyó, fue muy sañudo e muy maravillado, e díxole:

-Fijo, dezidme quien os lo á consejado.

E dixo él:

33 En español clásico, nada se emplea también con este significado, aunque no sea el más frecuente, al igual que cosa, convenientemente modificado: ligera cosa, cosa tan poca, poca cosa (Pérez-Salazar 2012).

34 Solo hay un caso más en el CORDE, en el siglo XX, también explicable por elipsis del verbo: Tan estúpidos como para no darse cuenta de que los presos eran ellos y no nadie más (1969. José Revueltas, El apando [El apando y otros relatos]). 
-Señor, no ninguno, mas yo sé bien que, si la matásedes, que sería gran mal e grand desacuerdo (1501. Anónimo, Tristán de Leonís)

61. [...] puntos y comas, que son como cruces en las encrucijadas para atinar el camino, ahora puestas fuera de su lugar, ahora en no ninguno (1528. Juan Justiniano, Instrucción de la mujer cristiana, de J.L. Vives) 62. [...] y viendo que cuanto más iba más ásperos caminos y no ninguna comida hallaba, determinó de acostarse a la corta del Sur (1544. Anónimo, Tercera relación anónima de la jornada que hizo Nuño de Guzmán [Documentos para la Historia de México])

63. Lavado al ñublo, secado al humo, lavado no ninguno (1549. Hernán Núñez, Refranes o proverbios en romance)

64. Esos kanpos de Moleras,/ ke son kanpos sin ventura,/ do berrean los korderos,/ las ovexas no ninguna (1627. Gonzalo Correas, Vocabulario de refranes y frases proverbiales)

No nada o nonada conoce sus mejores tiempos durante aproximadamente un siglo (de mediados del XVI a mediados del XVII). A juzgar por la heterogeneidad de las fuentes en que se encuentran las dos variantes, como también de los autores que las firman y de los hablantes que las utilizan en los pasajes dialogados, debía de emplearse sin restricciones de ningún tipo (génericas, sociales o situacionales). El predominio de una u otra representación depende del factor temporal, como se aprecia en la tabla 2 , de las preferencias de algunos autores ${ }^{35}$, y también del valor: no nada se emplea más como cuantificador, nonada como sustantivo ${ }^{36}$.

De las dos acepciones ya señaladas en su empleo como sustantivo, 'ausencia absoluta de todo ser' y 'cosa sin importancia', predomina llamativamente la segunda ${ }^{37}$, que, frente a lo observado para el siglo XV, es la que se construye ahora con actualizador ${ }^{38}$ :

35 Santa Teresa de Jesús y Cervantes, que lo emplean con frecuencia, lo representan casi siempre como unidad léxica; Boscán o Las Casas lo escriben habitualmente en dos componentes.

36 Desde la segunda mitad del siglo XVII la representación nonada solo se emplea como sustantivo, y así continúa en los siglos siguientes (cfr. infra).

37 Eberenz (2000: 424, n. 89) informa del uso de nonada en el Siglo de Oro sobre todo como sustantivo: 'cosa de poca monta', anota. Obsérvese que también se encuentra el plural nonadas.

38 Obsérvese, en el testimonio 70, el uso de nonada en un enunciado interrogativo-refutativo que incluye una coordinación disyuntiva. Este esquema fraseológico, característicamente oral, se emplea, como indica Olza (2011: 183) "para expresar desacuerdo o incredulidad respecto de lo enunciado en un segmento discursivo previo". El primer elemento reproduce lo dicho en la intervención anterior; el hueco del segundo lo ocupa un sustantivo cuyo valor es meramente 
65. Si Dios pudo hazer al hombre antes que fuese de nonada (1543-1548. Jorge de Montemayor, Diálogo espiritual)

66. [...] que contino se crían nuevas almas cada día y que nuestro Dios omnipotente las cría cada día de no nada (1547. Alonso de Fuentes, Suma de Filosofia natural)

67. ¿Y por una nonada que mi señora os ha dicho estáys ya desmayado? (1511. Anónimo, Traducción de Tirante el Blanco de Joanot Martorell) 68. Pues, como allí oygan a los marineros contar sus peligros, a los soldados contar sus victorias y batallas, y a otros baladrones que parlan de mil nonadas(1533. Bernardo Pérez de Chinchón, La lengua de Erasmo nuevamente romançada por muy elegante estilo)

69. [...] les daba después una flaca limosna y, con aquella nonada que de mí recebían, ganaba reputación para después mejor alzarme con haciendas ajenas (1604. Mateo Alemán, Segunda parte de la vida de Guzmán de Alfarache. Atalaya de la vida humana)

70. ¿Soys criado de algunos comediantes?

Respondió Sancho:

-¿Qué comediantes o qué nonada? (1614. Alonso Fernández de Avellaneda, Don Quijote de la Mancha)

Con este significado, es frecuente en función de atributo. Como tal, es susceptible de recibir un elemento ponderativo:

71. ¡Oh, válame Dios, y qué nonada son nuestros deseos para llegar a vuestras grandezas, Señor! (1566-1575. Santa Teresa de Jesús, Conceptos del amor de Dios)

72. [...] unos animalejos tan pequeños como son los mosquitos de una cierta especie, que apenas se dejan ver, y con ser tan nonada pican tan blandamente que [...] de allí a un rato os halláis hinchada la parte donde os picó (1588. Fray Pedro Malón de Chaide, La conversión de la Magdalena) 73. Aunque por ser yo nonada/ es tan corta y limitada/ esta privanza, que dudo/ que si yo mismo ahí acudo/ no mereceré posada (1617. Juan Valladares de Valdelomar, Caballero venturoso)

Aunque excepcionalmente, se utiliza con referente personal (recategorizado como común en cuanto al género), y modifica a otro sustantivo inmediatamente o a través de un índice verbal:

expresivo, bien un plural (narices), o un término que apunta a algo insignificante, como sucede aquí con nonada, o un término vulgar. 
74. [...] y era un hombrecillo tan no nada que aun de ruin jamás se veía harto (1653. Baltasar Gracián, El Criticón, segunda parte. Ivyziosa cortesana filosofia en el otoño de la varonil edad)

75. Era como del codo a la mano, un nonada, pigmeo en todo, en el ser y en el proceder (1657. Baltasar Gracián, El Criticón, tercera parte. En el invierno de la vejez)

Nonada se encuentra además en expresiones de valor temporal:

76. Yo affirmo ser verdad esso que dizes de las abusiones, que a cada nonada dizen a hombre que entra en el infierno (1536. Gaspar Gómez de Toledo, Tercera parte de la tragicomedia de Celestina)

77. [...] que con vna peñolada/ pudiera en vna no nada/ rentaros mas mi tintero/ que en toda estotra jornada (1550. Cristóbal de Castillejo, Romance [Primera parte de la Silva de varios romances])

78. Quántas vezes, pregunto yo, succede acabar de hazer un navío o una casa, y dentro de nonada está hirviendo de gusanos (1591. Juan de Cárdenas, Primera parte de los problemas y secretos maravillosos de las Indias)

Como cuantificador de existencialidad mantiene sus funciones pronominales y adverbiales. Si bien, como he indicado antes, predomina la representación no nada, la equivalencia de las dos ha prolongado sus límites: la forma lexicalizada aparece incluso en casos en los que la presencia del adverbio negativo se podría atribuir a una causa contextual (84 a 87), lo cual viene a demostrar que no se identifica, ni siquiera en estos casos, la forma adverbial como elemento ajeno al indefinido (obsérvese, en 86, la alternancia de nada y nonada):

79. Amigos, no lloréis, que con ello poco o no nada se cobrará de lo perdido (1504. Garci Rodríguez de Montalvo, Las sergas del virtuoso caballero Esplandián)

80. [...] y fue que un día, por una bolsa que furté a otro con casi no nada, fue tomado en el hurto y preso (1542. Anónimo, Baldo)

81. Agua de león. aunque gruesa y no nada fresca, por donde mojaba pasaba (1605. Francisco López de Úbeda, La pícara Justina)

82. Myopiassis, defecto dende el nacimiento por el qual ven de cerca y de lejos, poco, o no nada (1606. Juan Alonso y de los Ruyzes de Fontecha, Diez privilegios para mujeres preñadas)

83. [...] otros, que, aunque tuvieron principios grandes, acabaron en punta, como pirámide, habiendo diminuido y aniquilado su principio hasta parar en nonada, como lo es la punta de la pirámide (1615. Miguel 
de Cervantes, Segunda parte del ingenioso caballero don Quijote de la Mancha)

84. [...] son mis convites limpios y aseados y nonada escasos (1615 Miguel de Cervantes, Segunda parte del ingenioso caballero don Quijote de la Mancha)

85. Tobías no sea piadoso/ y Iob no nada sofrido (1622. José de Valdivielso, El nacimiento de la meior. Comedia divina [Doce actos sacramentales y dos comedias divinas])

86. Más vale algo ke nada; [o] ke nonada (1627. Gonzálo Correas, Vocabulario de refranes y frases proverbiales)

87. CELIA -Mi bien, ¿qué has hecho?

ENRICO -Nonada (1635. Tirso de Molina, El condenado por desconfiado)

La nómina de secuencias idiomáticas se ve también incrementada. A las mencionadas de nonada y por nonada, que continúan vigentes, hay que sumar la locución temporal en nonada, y a estas una fórmula pragmática de negación o rechazo, mas nonada (o mas no nada, entre otras variantes ${ }^{39}$ ), que, a juzgar por su presencia en diálogos literarios -esencialmente en obras dramáticas- debía de gozar de difusión en el intercambio oral de este tiempo $^{40}$ :

88. [...] en cosas de nonada confiados, / y en las otras medrosos y cuytados (1514-1542. Juan Boscán, Poesías)

89. Un airecillo de nonada arromadiza a un hombre y suele dar con él en la sepultura (1610-1612. San Juan Bautista de la Concepción, Exhortaciones a la perseverancia)

90. Perico. ¡Sal aquí, boticario de no nada! (1691. Anónimo, Entremés del pelicano y ratón)

91. ¿Por qué a éste por no nada tan cruelmente fieres, y cada hora sin tener razón ninguna feriendo nos matas, y tú ninguna cosa de bien fazes? (1520. Anónimo, Vida de Ysopo)

92. Bien creo que vos es notorio, leales varones y amigos, [...] como por nonada y sin causa necessaria los sobervios y ambiciosos cartaginenses,

39 En algunos testimonios del CORDE se transcribe mas, no nada y más nonada.

40 Correas la incluye en su repertorio: "Más nonada. Desdeña i niega" (Correas 1627). La fórmula mas nonada, de la que solo hay siete testimonios, se encuenta en secuencias dialogadas, y exepcionalmente en un pasaje monológico; obsérvese que entonces (testimonio 98) la refutación afecta a lo dicho inmediatamente por el mismo hablante. 
siendo su capitán uno llamado Baldo, vinieron a Dalmacia y allí ocuparon mucha tierra (1542. Anónimo, Baldo)

93. Cuatro horas que se ofrescía/ A morir por amor dél/ Y que con toda osadía/ Combatió por serle fiel;/Y en nonada,/ Aun no bien seca la spada,/ [...] Luego se fué retirando/ De su esfuerço para atrás (1547. Cristóbal de Castillejo, Aula de cortesanos)

94. En un santiamén. En un istante. En nonada. En kasi nada (1627. Gonzalo Correas, Vocabulario de refranes y frases proverbiales)

95. CLARA: [...] alguna de esas yeguas/ puede ensillar.

SOL: Mas, no nada (1598-1602. Lope de Vega Carpio, Los Benavides)

96. Don Alonso (Aparte.): ¡Cielos, valedme!

Don ToRIBIO: Vi...

Don Alonso: ¿Qué? ¿Al hombre?

Don ToRiBIo: ¡Mas nonada!/ ¿Verle y no darle la muerte? (1649. Pedro Calderón de la Barca, Guárdate del agua mansa)

97. PERICo: Escucha, Osuna:/ ha venido a la corte una condesa/ que un título pretende en casamiento,/ y aqueste he de ser yo.

Osuna: ¿Tú? ¡mas no nada! (1645. Luis Quiñones de Benavente, Entremés de los condes)

98. Ese público ayuno, y en secreto/ bocólico conceto,/ es peor que la gula duplicada; ése, hermano, ¿es ayuno? ¡Mas nonada! (1644. Antonio Enríquez Gómez, El siglo pitagórico y Vida de don Gregorio Guadaña)

Aparte de las mencionadas locuciones, nonada participa regularmente en otras unidades fraseológicas, las paremias; los repertorios de esta época de Vallés, Núñez y Correas registran un buen número de frases proverbiales en las que este elemento interviene como sustantivo o como cuantificador ${ }^{41}$ :

99. Más querría ser nonada que ser pobre y no tener nada (1549. Hernán Núñez, Refranes o proverbios en romance)

100. De lo poco / poco: de lo mucho / no nada (1549. Pedro Vallés, Libro de refranes)

101. A unos mucho, a otros nonada (1627. Gonzálo Correas, Vocabulario de refranes y frases proverbiales)

Este tiempo deja también testimonios del derivado homogéneo nonadilla, empleado, en los tres testimonios del CORDE en que se encuentra, con referente personal:

41 Es llamativo que en el Vocabulario de Correas se encuentren 51 de los 114 testimonios de nonada (o variantes) pertenecientes al siglo XVII. 
102. "Esta enfermedad pide sangría, mas es este cavallerito tan ruincillo i tan nonadilla, que no me atrevo a dárselas" (1631. Juan de Robles, El culto sevillano)

103. [...] porque el ignorante se imaginava sabio, con que no estava en sí, el nonadilla se creía gran hombre, el vil gran cavallero, la fea se soñava hermosa, la vieja niña, el necio mui discreto (1657. Baltasar Gracián, El Criticón, tercera parte. En el invierno de la vejez)

Pese a la difusión que parece alcanzar nonada en español clásico, y quizá por la limitación temporal a la que estuvo sujeta, lo cierto es que apenas se deja ver en fuentes americanas: nonada y no nada suman solo treinta y tres testimonios en todo el Siglo de Oro en textos escritos fuera de España ${ }^{42}$ (y, sin embargo, están representados todos los valores), de los que más de la mitad proceden de México. Obsérvese su presencia mayoritaria en la prosa historiográfica y notarial:

104. Mucho me holgaré yo de pelear por mi Dios contra vuestros dioses, que son nonada (1525. Andrés de Tapia, Relación hecha por el señor Andrés de Tapia, sobre la conquista de México [Documentos para la Historia de México]).

105. [...] e cómo unos indezuelos de nonada, chichimecas de la provincia de Xalisco, se habían alzado y rebelado (1541. Jerónimo López, Carta de Jerónimo López al emperador [Documentos para la Historia de México]). 106. De los quintos que hasta agora se han habido, no escribimos sobre ello ni los enviamos, por ser nonada (1545. Anónimo, Carta al Rey de los Oficiales Reales de Chile...)

107. [...] desta enfermedad ay casi muy poco o no nada (1566-1569. Anónimo, Carta sobre el alzamiento de los Chiriguanaes [Documentos para la historia lingüistica de Bolivia])

108. Los bienes: una chacara de coca Opoata las 2 mitas del año dos cestos y la de ahora no nada (1568-1570. Anónimo, Visita de los valles de Sonqo en los yunka de coca de la Paz. Perú)

109. [...] porque como vnos tomasen algo y otros no nada, quisieran los que no tuvieron ningun aprobechamiento que todo se partiera (15731581. Fray Pedro de Aguado, Historia de Santa Marta y Nuevo Reino de Granada. Colombia)

42 La distribución es la que sigue: de los 17 testimonios de nonada (todos del siglo XVI), 14 proceden de México, 2 de Chile, 1 de Perú y 1 de Colombia. No nada se encuentra en 15 ocasiones (11 en el siglo XVI); 5 en fuentes procedentes de México, 6 de Perú, 2 de Colombia, 1 de Bolivia y 1 de Venezuela. 
110. Teresa. ¡Qué marido y qué señor!/ Maridillo de nonada (1600. Fernán González de Eslava, Coloquio séptimo de cuando Dios Nuestro Señor mandó al profeta Jonás que fuese a la ciudad de Nínive... México.) 111. Es fruta basta, no nada delicada ni regalada (1609. Inca Garcilaso, Comentarios Reales de los Incas. Perú.)

112. [...] vino un bachillerejo de no nada y les cortó las cabezas (1627. Fray Pedro Simón, Primera parte de noticias historiales de las conquistas de tierra firme en las Indias Occidentales. Venezuela).

3.2. La extensión y la lexicalización de nonada tienen otra consecuencia en el Siglo de Oro: su entrada en los repertorios lexicográficos. Al comenzar el siglo XVII, este elemento se incluye en diccionarios monolingües y bilingües. En cambio, no se encuentran referencias a la combinación de no y nada en las gramáticas de este tiempo, ni se incluye nonada en la nómina de los indefinidos ${ }^{43}$. El mismo Correas, que, como he señalado antes, se sirve de nonada en su propio discurso y deja abundantes testimonios de su presencia en el ámbito fraseológico, y que incluso aporta, en su Vocabulario, datos imprescindibles sobre el valor del este elemento (cfr. infra), lo deja fuera del grupo de cuantificadores de existencialidad en su Arte de la lengua española castellana, y solo lo incorpora para la descripción del indefinido nada (1626: 185): "Nada niega cosa, i sirve de neutro, que en forma feminina en la qual se adjetiva: mucha nada i mucha nonada, con lo que del dixe poco antes rrepetido aqui por neutro de nadie".

Mucho más explícitos, los diccionarios dan cuenta del carácter multicategorial y de los significados de nonada ${ }^{44}$.

Covarrubias, riguroso en su descripción (1611: s.v. nonada y nada), lo presenta como sustantivo que significa 'lo que es de poco momento', pero también como indefinido que concurre con la forma simple nada: "También

43 Según he podido comprobar, no se encuentran referencias a las combinaciones no ninguno o no nada y a la unidad nonada en las gramáticas de Villalón (1558), Jiménez Patón (1614) y Juan Villar (1651) y tampoco, más adelante, en la de la Real Academia de 1771 -que sí trata casos de negación expletiva (RAE 1771: 351) pero no incluye testimonios de no + indefinido negativo-, o en la de Andrés Bello (1847).

44 La consulta de la voz nonada en los diccionarios que relaciono aquí y en $\S 4.2$. se ha realizado a través del NTLLE de la Real Academia Española en su versión en DVD-ROM, salvo los de Covarrubias (1611), Cuervo (1886-1994) y la edición vigésima segunda del Diccionario de la RAE. Incorporo en el apartado "Referencias bibliográficas" los datos de estas obras. En cuanto a las ediciones del Diccionario académico (en sus versiones usual y manual) incluyo en ese apartado la primera y la última, y remito a la aplicación del NTLLE en línea (www.rae. es) para información bibliográfica. 
dezimos nonada, y significa lo mesmo". Correas anota este último valor en su Vocabulario (Correas 1627: s.v.) "Uno nada, y otro nonada. Por ambigüedad tiene grazia: "nonada" es ninguna kosa; i "no nada" es ke no sabe nadar".

En cuanto a los diccionarios bilingües, la entrada de nonada es general. Oudin (1607) y Vittori (1609) lo señalan como sustantivo (una nonada en ambos) y también registran el plural nonadas. Para Minsheu (1617) y Franciosini (1620), nonada es indefinido, como nihil, nothing y niente (o incluso non niente, anota el último).

\section{LA SUERTE DE NONADA DESDE EL SIGLO XVIII}

4.1. El repentino retroceso que nonada y no nada experimentan a partir de los últimos decenios del Siglo de Oro es, según apuntan los datos hallados en el CORDE, irreversible. La discreta presencia a la que se ven reducidas ambas representaciones en los textos continúa en español moderno y contemporáneo. La diversidad categorial y funcional que habían alcanzado se reduce, como es obvio, con la pérdida de testimonios, y aunque todavía está representada buena parte de los valores y funciones adquiridos (con una distribución entre las dos variantes mucho más clara), se produce también una llamativa regresión textual. No nada y nonada quedan fuera de las manifestaciones escritas de la oralidad hasta el siglo XX, y se limitan, casi sin excepción, a la creación literaria (en particular, la narrativa) y a la prosa ensayística o científica.

La forma lexicalizada se encuentra únicamente como sustantivo, mientras que no nada aparece como cuantificador y, ocasionalmente, como sustantivo. De las secuencias fraseológicas, la única que permanece a partir del siglo XVIII es la locución adjetiva de nonada ${ }^{45}$.

Como se observa en la tabla 3 , solo nonada alcanza los cincuenta testimonios, considerando los datos globales, en español moderno y contemporáneo ${ }^{46}$ :

45 Como he señalado en n. 22, nada ocupa su lugar también en estas locuciones. Así, el español conserva de nada (aunque de nonada se encuentra, a la vista de lo hallado en el CORDE y el CREA, hasta la actualidad), en nada y por nada (del mundo), como se explica en Pérez-Salazar (2013: § 3.2).

46 En cuanto a la distribución geográfica, los textos del CORDE en los que se encuentran nonada y no nada proceden mayoritariamente de España. Solo un $10 \%$ del total corresponde 
Tabla 3. No nada y nonada en español moderno y contemporáneo

\begin{tabular}{|c|c|c|}
\hline & no nada & nonada(s) \\
\hline Siglo XVIII & 14 & 2 \\
\hline Siglo XIX & 7 & 22 \\
\hline Siglo XX (-1975) & 11 & 29 \\
\hline
\end{tabular}

En el siglo XVIII, los escasos testimonios de no nada se encuentran esencialmente en textos didácticos ${ }^{47}$; nonada en esta centuria es excepcional:

113. [...] que aun después de tenerlo todo, todo lo tiene por nada, por un no nada que le falte (1703. Francisco Garau, El sabio instruido de la Gracia) 114. [...] ordenó no sé qué emplastos de harinas y otros ingredientes que se me aplicaron en aquella parte, y no sé cómo me curarían una cosa de no nada (1705. Raimundo de Lantery, Memorias)

115. [...] quien afianza la gracia es la limpieza de corazon, yo no nada callo (de lo que es de hablar) à V. Mag. (1730. Francisco Máximo de Moya Torres y Velasco, Manifiesto universal de los males envejecidos que España padece)

116. [...] del cual salieron al acercarnos seis o siete hombres no nada inermes (1789. Leandro Fernández de Moratín, La derrota de los pedantes)

117. Ni yo la vi jamás, que se apropiasse/ Una auja, un dedal, una nonada (1774. José Francisco de Isla, El Cicerón)

118. Y ¿qué es, Hafiz, tu vida?/ Moneda de nonada ${ }^{48}$ (1799-1815. Conde de Noroña, Poesías)

Un siglo después, nonada vuelve a aumentar su presencia, sobre todo en la narrativa. La representación en dos componentes, muy poco visible ${ }^{49}$,

a América, en el que están representados, en porcentaje similar, varios países: Colombia, Perú, Venezuela, Chile, Ecuador y México.

47 Además, de los catorce testimonios de no nada, ocho pertenecen a la misma obra, $E l$ sabio instruido de la gracia, del jesuita Francisco Garau. La difusión es, por tanto, bastante escasa.

48 El editor explica, en nota, el significado de la expresión moneda de nonada: es la denominación que se da a una moneda mala que se arroja en celebraciones populares, costumbre, señala, que se ha tomado de oriente.

49 De los ocho testimonios del CORDE, cinco aparecen en la misma obra, Viajes de Fray Gerundio por Francia, Bélgica, Holanda y orillas del Rhin, de Modesto Lafuente. No incluyo en el cómputo de este siglo los dos testimonios de Boscán que reproduce Andrés Bello: ¿De qué se enfada?/ Respondió riendo de no nada. Mira bien que será de nuevo hacella,/ y que será hacella de no nada (1865. Andrés Bello, Notas sobre Boscán [Estudios gramaticales y 
se emplea como cuantificador, y solo en función adverbial. La alternancia formal se limita a la locución adjetiva:

119. Mas porque vuestra fantasía no tenga que viajar, hender los aires y el espacio, y fatigarse por cosa de nonada y fruslería (1847. Serafín Estébanez Calderón, Escenas andaluzas, bizarrías de la tierra, alardes de toros, rasgos populares, cuadros de costumbres...)

120. Por ende, ordenaba el monarca se notificase a todos los estantes y habitantes de su muy noble ciudad de los Reyes del Perú que en término de treinta días (¡ahí es nonada la prisa!) abandonasen el regalo de la vida célibe (1877. Ricardo Palma, Tradiciones peruanas, cuarta serie) 121. ¡Se le había concluido esa cosa tonta y divina, esa farándula indispensable, esa nonada omnipotente que llaman dinero! (1883. Benito Pérez Galdós, El doctor Centeno)

122. Despierta, Pelegrin, le dije, acompañando el llamamiento verbal con una mamola no nada suave (1842. Modesto Lafuente, Viajes de fray Gerundio por Francia, Bélgica, Holanda y orillas del Rhin)

123. [...] a quien sus palaciegos le delineaban como la suma de los vicios, inepto además y no nada a propósito para el empleo de que estaban tratando (1880-1882. Juan Montalvo, Las catilinarias)

El siglo XX continúa la misma tendencia. En su discreta presencia, el reparto de valores de las dos formas es el ya señalado -nonada, sustantivo ('cosa de escasa importancia', más documentado en plural); no nada, cuantificador, menos frecuente-. Eso sí, aunque ocasionalmente, las dos recuperan un espacio en pasajes dialogados ( $\mathrm{y}$, por cierto, en boca de hablantes socialmente heterogéneos):

124. [...] y se contaba como caso de dominación el de cierto muchacho que obligó a otro a lamer una piedra ensalitrada de correr por ella aguas no nada limpias (1908, Miguel de Unamuno, Recuerdos de niñez y de mocedad)

125. [...] obligaba a que María fuese sin su marido: cosa muy disonante de las costumbres de su pueblo y no nada expuesta a críticas o murmuraciones (1916, Antolín López Peláez, La vida de la Virgen)

126. Tú bien lo has dicho, ipos si los diamantes no nada más van a ser nuestros! (1973. Arturo Azuela, El tamaño del infierno)

lingüísticos]), y tampoco el que sigue, de J. Hellín, en el que se emplea no-nada con un valor que difiere de lo visto hasta aquí: Y esta razón superior es la oposición a la nada, la no-nada (1947. José Hellín, La analogía del ser y el conocimiento de Dios en Suárez). 
127. -Pues bien, sí, que Federico me ha quitado la novia.

- ¿Federico Vargas?

- El mismo.

- ¿Y a eso denominas nada, no cosa nada, nonada? ¿Y dejas que ese.... esportulario del espíritu te birle la novia? ¿Y así lo dejas? (1902. Miguel de Unamuno, Amor y pedagogía)

129. Sin embargo, un recuerdo contemplativo -un sabor, un perfume, cualquiera nonada, la tibia música de un beso seguido de un ¿me quieres? dicho en voz queda, en deleitosa intimidad (1929. Salvador González Anaya, La oración de la Tarde)

129. [...] uno de mis amigos, que prepara actualmente una novela de asunto andaluz, se halla preocupado por una verdadera nonada (1948. Emilio García Gómez, Nuevas escenas andaluzas)

130. Precisamente Sixto García, al ridiculizar-aun cuando fuera de modo muy elemental- las boberías y nonadas en que ocupaban su tiempo los cortejos (1972. Carmen Martín Gaite, Usos amorosos del dieciocho en España)

A partir de 1976, nonada mantiene su escasa presencia sin apenas variación ${ }^{50}$; se encuentra como sustantivo, en empleo libre y en la locución de nonada. Los datos del CREA lo sitúan, como hasta ahora, esencialmente en obras literarias, y excepcionalmente en la prensa. No hay rastro de este elemento en realizaciones orales reales:

131. Y con la última nonada suscitada por la última nota del clavecín, Wenceslao, abriendo los brazos, se lanzó a abrazar a su madre (1978. José Donoso, Casa de Campo)

132. CHANFALLA. Todo el secreto de un buen embuste yace en aquel esmerarse y atar corto las minucias. De ahí, de las nonadas, procede la apariencia de ser algo verdadero, que no en fingirlo a bulto y sin mesura (1985. José Sanchís Sinisterra. El retablo de Eldorado)

133. -No tengas ningún miedo -respondía Efrén Castells-; conozco bien a las hembras: engañan a sus maridos por una nonada (1986. Eduardo Mendoza, La ciudad de los prodigios)

134. Dícese del hombre blandengue, apocado, nonada, enmadrado o dominado por las "tietas" (1996. El Mundo, 31/03/1996: Catalán de urgencia: 50 palabras para manejarse en Barcelona)

50 Hay diez testimonios de este elemento en el CREA. Esta base de datos no me ha permitido acceder a los testimonios de la combinación no nada. 
135. [...] collarejos y otras cosas de nonada (2001. Juan Miralles, Hernán Cortés. Inventor de México)

4.2. Resulta paradójico que la participación más pobre en los textos coincida con la atención lexicográfica más generosa. Pese a que los datos confirman que el uso de nonada y no nada se reduce drásticamente, la unidad léxica conserva un lugar en los repertorios desde el siglo XVIII; es más, la primera referencia sobre restricciones de uso no aparece hasta bien entrado el siglo XIX, y aún después de esta constancia, que, por cierto, es excepcional, el lema se mantiene hasta nuestros días ${ }^{51}$.

Los dicccionarios bilingües de Sobrino (1705), Stevens (1706) y Bluteau (1721) lo señalan como indefinido: "Le même que nada", apunta Sobrino; y Stevens añade: "is next to nothing".

La Academia incorpora nonada -que vincula con un origen latino non nihil ${ }^{52}$ - en la primera edición del Diccionario (RAE 1726-1770: s.v.) únicamente como sustantivo femenino ('poco o muy poco'); como tal se mantiene hasta la vigésima segunda: 'cosa de insignificante valor' (RAE 2001: s.v.). Desde la primera edición hasta la de 1869 se incluye además una entrada nonadilla -diminutivo, "para mayor expresión de la poquedad"(NTLLE: S.v., en www.rae.es), cuya presencia en los textos, muy escasa según he observado, se limita al Siglo de Oro (cfr. supra).

Otros repertorios del mismo tiempo aportan algún dato más ${ }^{53}$ : Terreros y Pando (1787) interpreta nonada como 'casi nada' (y añade la equivalencia con "presque rien y un rien"). Este diccionario incluye, además, una forma lexicalizada nonadie ("lo mismo que nonada"), de la que no encuentro otras noticias y que, según he podido comprobar, no tiene ninguna presencia en el CORDE $^{54}$. Salvá (1846) informa del uso esporádico de nonada con el artículo masculino, que se ha documentado en el Siglo de Oro (testimonios 74 y 75), y Domínguez (1853) es más explícito en la descripción de su valor: "un poco, muy poco, una pequeña cantidad, una porción insignificante". Es precisamente este autor el primero que incorpora una restricción, que,

51 Las gramáticas no mencionan un indefinido nonada o no nada tampoco a partir del siglo XVIII, como ya sucedía con las del Siglo de Oro (véase nota 43).

52 Sobre la doble negación en latín véase García Cornejo (2009: 357-360).

53 La misma información que el Diccionario usual de la Academia aportan los de Núñez de Taboada (1825), Salvá (1846), Gaspar y Roig (1855), Zerolo (1895), Toro y Gómez (1901), Alemany y Bolufer (1917) y Pagés (1902-1931), según he podido comprobar en el NTLLE.

54 Cfr. supra sobre no nadie. En cualquier caso, me propongo comprobar su presencia en otras fuentes. 
curiosamente, no es social ni situacional, sino geográfica: "esta voz no es usual en todas las provincias de España". Por fin, Cuervo (1886-1994: s.v.) anota y ejemplifica todos los valores de este sustantivo y cuantificador, y menciona incluso la posibilidad de que se utilice con referente personal, pero no refiere restricciones de ningún tipo.

En la edición del Diccionario usual de 1884, la Academia suprime nonadilla, y sitúa el origen de nonada en la combinación de no y nada. No varía, sin embargo, la información sobre este elemento hasta 1984; es entonces cuando se añade, en el Diccionario usual y en el manual, un segundo valor, el de pronombre indefinido -documentado, según se ha visto, desde la Edad Media-, del que se indica que está en desuso (NTLLE: s.v., en www.rae.es).

Nonada se encuentra también en el Diccionario de María Moliner (1990: s.v.), que lo presenta como nombre calificativo y anota estas acepciones: "Pequeñez. Cantidad muy pequeña de una cosa. Chuchería. Cosa de muy poca importancia". Por fin, es muy acertada la restricción que señalan Seco, Andrés y Ramos (1999: s.v.), "literario", ya que, según se ha observado, coincide con los datos hallados en los últimos siglos en las fuentes consultadas.

\section{FINAL}

En la forma nonada intervienen los componentes no y nada, cuya combinación puede sorprender desde la perspectiva del español actual, pero cobra sentido si se analiza diacrónicamente. Este elemento resulta, por tanto, de un proceso de lexicalización, en el que la combinación del adverbio y el indefinido da lugar a un cuantificador y sustantivo en el que no se percibe la presencia de dos componentes ${ }^{55}$.

El examen histórico ha permitido observar los primeros testimonios del encuentro del adverbio negativo y los cuantificadores ninguno y nada, y con posterioridad, las primeras manifestaciones de la unidad léxica nonada. La concurrencia inmediata del adverbio no(n) y los existenciales ninguno y nada se produce en la Edad Media (cuando, según se ha dicho, estos indefinidos no estaban marcados negativamente), y se explica por circunstancias 
contextuales -casos de elipsis verbal y oraciones comparativas- que se dan en moldes textuales muy diversos. Sin apenas desfase, se encuentran testimonios en los que los cuantificadores reciben directamente el refuerzo del adverbio no(n). Abierta la posiblidad de que no y ninguno o nada se sucedan inmediatamente, las combinaciones no ninguno y no nada se propagan, pero solo la última da lugar a un nuevo elemento que, representado como unidad léxica o en dos componentes, se utiliza como cuantificador y como sustantivo. La aparición repentina de nonada sustantivo en secuencias fraseológicas lleva a pensar que su difusión en el intercambio oral fue anterior a lo que se refleja en el medio escrito.

Nonada multiplica su presencia, y con ella sus funciones y valores en empleo libre y en secuencias fraseológicas, hasta alcanzar la plenitud en español clásico. Es en la literatura del Siglo de Oro (en particular en los diálogos teatrales) y en los repertorios fraseológicos donde mejor se aprecia la variedad de usos de nonada en este tiempo. El retroceso de no nada y nonada sucede al concluir este periodo, cuando el paradigma de los indefinidos de existencialidad se configura definitivamente como el grupo de seis elementos que perdura hasta nuestros días.

\section{REFERENCIAS BIBLIOGRÁFICAS}

\section{FUENTES}

Real Academia Española, Banco de datos. CORDE. Corpus diacrónico del español, http:// www.rae.es (X-2013). rae.es (X-2013).

\section{DiCCIONARIOS, REPERTORIOS Y GRAMÁTICAS}

Alemany y Bolufer, José. 1917. Diccionario de la Lengua Española. Barcelona: Ramón Sopena.

Bello, Andrés y Rufino José Cuervo. 1954 [1847]. Gramática de la lengua castellana. Edición completa, esmeradamente revisada, corregida y aumentada con un prólogo y frecuentes observaciones de Niceto Alcala-Zamora y Torres. 4. ${ }^{\mathrm{a}}$ ed. Buenos Aires: Sopena Argentina.

Bluteau, Raphael. 1721. Diccionario castellano y portugues para facilitar a los curiosos la noticia de la lengua latina, con el uso del vocabulario portugues y latino [...]. Lisboa: Pascoal da Sylva.

Corominas, Joan. 1987-1991. Diccionario crítico etimológico castellano e hispánico. Madrid: Gredos. 
Correas, Gonzalo. 1954 [1626]. Arte de la lengua española castellana. Edición y prólogo de Emilio Alarcos García. Madrid: CSIC.

2000 [1627]. Vocabulario de refranes y frases proverbiales (1627). Edición de Rafael Zafra. [Edición en DVD-ROM]. Pamplona/Kassel: Universidad de Navarra/Edition Reichenberger/Ediciones digitales del GRISO.

CovarRubias, Sebastián DE. 2006 [1611]. Tesoro de la lengua castellana o española. Edición integral e ilustrada de Ignacio Arellano y Rafael Zafra. Madrid/Frankfurt: Iberoamericana/ Vervuert.

Cuervo, Rufino José. 2002 [1886-1994]. Diccionario de construcción y régimen de la lengua castellana [Edición en DVD-ROM]. Barcelona: Herder.

Domínguez, Ramón Joaquín. 1853. Diccionario Nacional o Gran Diccionario Clásico de la Lengua Española. 5. ${ }^{a}$ ed. Madrid-París: Establecimiento de Mellado.

Franciosini, Lorenzo. 1620. Vocabolario español-italiano, ahora nuevamente sacado a luz [...] Segunda parte. Roma: Iuan Pablo Profilio, a costa de Iuan Ángel Rufineli y Ángel Manni.

Gaspar y Roig. 1855. Biblioteca Ilustrada de Gaspar y Roig. Diccionario enciclopédico de la lengua española, con todas las vozes, frases, refranes y locuciones usadas en España y las Américas Españolas [...]. Madrid: Imprenta y Librería de Gaspar y Roig.

JimÉnez PATÓN, BARTOLOMÉ. 2001 [1614]. Institvciones de la gramática española [Recurso electrónico]. Madrid: Fundación Histórica Tavera / Digibis

Moliner, María. 1990. Diccionario de uso del español. Madrid: Gredos.

Minsheu, John. 1617. Vocaublarium Hispanicum Latinum et Anglicum copiossisimum, cum nonnullis vocum millibus locupletatum, ac cum Linguae Hispanica Etymologijs [...]. London: Joanum Browne.

NTLLE $=$ Real Academia Española. 2001. Nuevo Tesoro Lexicográfico de la Lengua Española [Edición en DVD-ROM]. Madrid: Espasa.

NúÑ̃Z de TABOAda, M. 1825. Diccionario de la lengua castellana, para cuya composición se han consultado los mejores vocabularios de esta lengua [...]. París: Seguin.

OUdIN, CÉSAR. 1607. Tesoro de las dos lenguas francesa y española. Thrésor des deux langues françoise et espagnolle. París: Marc Orry.

Pagés, ANICETo. 1902-1931. Gran diccionario de la lengua castellana, autorizado con ejemplos de buenos escritores antiguos y modernos [...]. Madrid: Sucesores de Rivadeneyra.

Real ACAdEMia Española. 1726-1770. Diccionario de la lengua castellana, en que se explica el verdadero sentido de las voces, su naturaleza y calidad, con las prhases o modos de hablar [...]. Madrid: Imprenta de Francisco del Hierro.

1771. Gramática de la lengua castellana. Madrid: D. Joachin de Ibarra, impresor de Cámara de S.M.

2001. Diccionario de la lengua española. 22. ${ }^{\text {a }}$ ed. Madrid: Espasa.

SALVÁ, ViCENTE. 1846. Nuevo diccionario de la lengua castellana, que comprende la última edición integra, muy rectificada y mejorada del publicado por la Academia Española [...]. París: Vicente Salvá.

Seco, Manuel, Olimpia Andrés y Gabino Ramos. 1999. Diccionario del español actual. Madrid: Aguilar.

Sobrino, Francisco. 1705. Diccionario nuevo de las lenguas española y francesa. Bruselas: Francisco Foppens.

Stevens, John. 1706. A new Spanish and English Dictionary. Collected from the Best Spanish Authors Both Ancient and Modern [...]. London: George Sambridge.

Terreros y PANDo, Esteban. 1787. Diccionario castellano con las voces de ciencias y artes y sus correspondientes de las tres lenguas francesa, latina e italiana. Tomo segundo. Madrid: Imprenta de la viuda de Ibarra, hijos y compañía. 
Toro y Gómez, Miguel De. 1901. Nuevo diccionario enciclopédico ilustrado de la lengua castellana. París-Madrid: Librería Armand Colin-Hernando y Cía.

Villalón, Cristóbal. 2001 [1558]. Gramática Castellana [Recurso electrónico]: arte breue y compendiosa para saber hablar y escreuir en la lengua Castellana congrua y decentemente. Madrid: Fundación Histórica Tavera: Digibis.

VILlaR, JuAn. 2001 [1651]. Arte de la lengva española redvcida a reglas y preceptos de rigurosa gramatica [Recurso electrónico]. Madrid: Fundación Histórica Tavera: Digibis.

Vittori, Girolano. 1609. Tesoro de las tres lenguas francesa, italiana y española. Thresor des trois langues françoise, italienne et espagnolle. Ginebra: Philippe Albert y Alexandre Pernet.

Zerolo, Elías. 1895. Diccionario enciclopédico de la lengua castellana. París: Garnier hermanos.

\section{OTRAS REFERENCIAS BIBLIOGRÁFICAS}

Alcón, Damián. 1920. Pequeñeces del lenguaje: res, cosa, nada. Boletín de la Real Academia Española 7: 544-546.

Alvar, Manuel. 1953. El dialecto aragonés. Madrid: Gredos.

Alvar, Manuel y Bernard Pottier. 1987. Morfología histórica del español. 1. a reimpr. Madrid: Gredos.

Anscombre, Jean Claude. 1997. Reflexiones sobre la naturaleza y el funcionamiento de las paremias. Paremia 6: 43-54.

Bosque, Ignacio. 1980. Sobre la negación. Madrid: Cátedra. 171-199.

Brucart, José María. 1999. La elipsis. En Ignacio Bosque y Violeta Demonte (dirs.). Gramática descriptiva de la lengua española, pp. 2787-2863. Madrid: Espasa-Calpe.

Camus Bergareche, Bruno. 1986. Cronología y extensión de un cambio en la expresión de la negación en la Romania. Universidad de La Laguna. Revista de Filología 5: 111-122. 1987-88. Negación doble en la romania: un cambio sintáctico. Revista de Filología Románica 5: 11-28.

2006. La expresión de la negación. En Concepción Company (dir.). Sintaxis histórica de la lengua española. $1^{a}$ parte. La frase verbal, pp. 1163-1249. México, D. F.: UNAM.

Company, Concepción. 2009. Los indefinidos compuestos y los pronombres genéricoimpersonales onme y uno. En Concepción Company (dir.). Sintaxis histórica de la lengua española. $2^{a}$ parte. La frase nominal, pp. 1075-1219. México, D. F.: UNAM.

Corblin, Francis y Lucía M. Tovena. 2003. L'expression de la négation dans les langues romanes. En Danièle Godard (ed.). Les langues romanes: problèmes de la phrase simple, pp. 281-343. Paris: CNRS Editions.

Eberenz, Rolf. 2000. El español en el otoño de la Edad Media. Sobre el artículo y los pronombres. Madrid: Gredos.

Elvira, Javier Enrique. 2006. Aproximación al concepto de lexicalización. En Javier Rodríguez Molina (ed.). Actas del IV Congreso Nacional de la Asociación de Jóvenes Investigadores de Historiografía e Historia de la Lengua Española, pp. 21-42. Madrid: Síntesis.

Enguita Utrilla, José María. 2004. Evolución lingüística en la Baja Edad Media: aragonés, navarro. En Rafael Cano (coord.). Historia de la lengua española, pp. 571-592. Barcelona: Ariel. 
Espinosa Elorza, Rosa María y Cristina Sánchez Lancis. 2006. Cuantificadores indefinidos en la General Estoria (Tercera parte). Revista de la Sociedad Española de Lingüística 36: $127-156$.

García CoRnejo, Rosalía. 2009. La negación y las palabras negativas nunca, ninguno, nada y nadie: una reinterpretación. Verba 36: 353-395.

García-Page, Mario. 2008. Introducción a la fraseología española. Estudio de las locuciones. Barcelona: Anthropos.

Girón Alconchel, José Luis. 2004. Cambios gramaticales en los siglos de oro. En Rafael Cano (coord.). Historia de la lengua española, pp. 859-893. Barcelona: Ariel.

Keniston, Hayward. 1937. The syntax of Castilian prose. The sixteenth century. Chicago: The University of Chicago Press.

Llorens, Eduardo L. 1929. La negación en español antiguo con referencia a otros idiomas. Madrid: Revista de Filología Española [Anejo 11].

Malkiel, Yakov. 1945. Old Spanish nadi(e), otri(e). Hispanic Review 13: 204-230.

1948. Hispanic 'algu(i)en'and Related Formations. A Study of the Stratification of the Romance Lexicon in the Iberian Peninsula. Berkeley: University of California Press.

Martins, Ana María. 1997. Aspectos da negaçao na história das linguas románicas. (Da natureza de palavras como nenhum, nada, ninguém). En Ivo Castro (ed.). Actas do XII Encontro Nacional da Associação Portuguesa de Linguística. Vol. 2: Linguística Histórica e História da Linguística, pp 179-210. Lisboa: Associação Portuguesa de Linguística.

Montgomery, Thomas. 1965. A Datum for the history of Castilian alguien and nadie. Hispanic Review 33: 52-57.

Montoro del Arco, Esteban Tomás. 2006. Teoría fraseológica de las locuciones particulares. Las locuciones prepositivas, conjuntivas y marcadoras en español. Frankfurt am Main: Peter Lang.

Morant Marco, Ricard. 1993. La negación en catalán. València: Universitat de València.

OlzA, INÉs. 2011.jQué fraseología ni qué narices!: fraseologismos somáticos del español y expresión del rechazo metapragmático. En Antonio Pamies Bertrán, Juan de Dios Luque Durán y Patricia Fernández Martín (eds.). Paremiología y herencia cultural, pp: 181-191. Granada: Granada Lingvistica.

Pérez-Salazar, Carmela. 2007. La expresión de la existencialidad en cartas privadas (siglos XVII-XVIII). Creatividad y evolución. En Luis Cortés Rodríguez et alii (eds.). Discurso y Oralidad. Homenaje al profesor José Jesús de Bustos Tovar, pp. 401-416. Madrid: Arco/Libros.

2012. Nada, cosa y nonada en español clásico. Aproximación desde los textos dramáticos del Siglo de Oro. Ponencia presentada en el IX Congreso Internacional de Historia de la Lengua Española. Cádiz, España.

2013. Sobre las fórmlas nada de eso, por nada (del mundo). Cronología, valores y especialización pragmática. En Inés Olza y Elvira Manero (eds.). Fraseopragmática, pp. 231-261. Berlin: Frank \& Timme.

Posner, ReBeCCa. 1985. Histoire de la négation et typologie romane. En Linguistique comparée et typologie des langues Romanes. Actes du XVIIe Congrès de Linguistique et Philologie Romane, II, pp. 265-271. Aix-en-Provence: Université de Provence.

Raya García, Irene. 1992. Contribución al estudio de los indefinidos en castellano medieval. En Manuel Ariza (coord.). Actas del II Congreso Internacional de Historia de la Lengua Española I, pp. 771-983. Madrid: Gredos.

Ricós Vidal, Amparo. 2002. Construcciones impersonales en el español medieval y clásico: estructuras con omne, se y uno. En María Teresa Echenique y Juan Méndez (eds.). Actas del V Congreso Internacional de Historia de la Lengua Española, pp. 945-958. Madrid: Gredos. 
2003. No lo digas a ánima viva: indefinidos existenciales en castellano medieval y clásico. En Fernando Sánchez Miret (ed.). Actas del XXIII Congreso Internacional de Lingüística y Filología Románica II-2, pp. 259-270. Tübingen: Max Niemeyer Verlag.

Ridruejo, Emilio. 1989. Las estructuras gramaticales desde el punto de vista histórico. Madrid: Síntesis.

RuEDA, MERCEDEs. 1997. Los términos negativos en español: aproximación diacrónica. León: Universidad de León.

SÁnChez López, CRistina. 1999. La negación. En Ignacio Bosque y Violeta Demonte (dirs.). Gramática descriptiva de la lengua española, pp. 2561-2634. Madrid: Espasa Calpe.

SARAlegui, CARmen. 1977. El dialecto navarro en los documentos del monasterio de Irache (958-1397). Pamplona: Institución Príncipe de Viana.

SolÀ, Joan. 1973. Estudis de Sintaxi catalana. 2. Barcelona: Edicions 62.

WagenaAR, Kornelis. 1930. Étude sur la négation en ancien espagnol jusqu'au Xve siècle. Groninga-La Haya: J.B. Wolters. 